\title{
1. LOS VALORES EN EL SISTEMA DE DERECHOS
}

HUMANOS

GERMÁN J. BIDART CAMPOS

\section{y}

DANIEL E. HERRENDORF 


\section{SUMARIO}

I. EL SISTEMA DE DERECHOS HUMANOS.-II. L A NECESIDAD DE LA AXIOLOGIA.-III. El ÁmBITO dONDE RADICAN LOS VALORES.-IV. EL SISTEMA DE DERECHOS HUMANOS EN LA REALIDAD DE LAS CONDUCTAS.-V. EL CONJUNTO CULTURAL DE UNA SOCIEDAD Y LOS VALORES.-VI. EL DEBER SER EXISTENCIAL.-VII. LA FUNCIÓN LEGITIMADORA DE LOS DERECHOS HUMANOS.-VIII. LOS VALORES Y EL “OBJETIVISMO". - IX. SISTEMA DEMOCRATICO, DERECHOS HUMANOS Y VALORES.-X. La historicidad de LOS VAlORES.-XI. Epílogo. 


\title{
1. LOS VALORES EN EL SISTEMA DE DERECHOS HUMANOS
}

\author{
POR \\ GERMÁN J. BIDART CAMPOS * \\ y \\ DANIEL E. HERRENDORF **
}

\section{EL SISTEMA DE DERECHOS HUMANOS}

Convencionalmente aceptado — como es habitual actualmente-que en torno de los derechos humanos existe una trilogía compuesta por la filosofía de los derechos humanos, la ciencia de los derechos humanos y el derecho de los derechos humanos (dividido este último en derecho constitucional y derecho internacional) ${ }^{1}$, conviene aclarar que aquí emplearemos la locución "sistema de derechos humanos" como equivalente a un sistema jurídico-político ${ }^{2}$ en el que los derechos humanos son una realidad efectiva o vigente en dimensión sociológica, porque las conductas —que siempre se despliegan con juridicidad $-{ }^{3}$ confirman esa realidad efectiva y esa vigencia sociológica.

* Profesor de Derechos Humanos y Garantías, y de Teoría del Estado en la Universidad de Buenos Aires. Argentina.

** Profesor de la Universidad Nacional Autónoma de México y de la Universidad Iberoamericana. México D. F.

1 Ver, de nuestra coautoria, el libro Principios de Derechos Humanos y Garantías, Ed. Ediar, Buenos Aires.

2 Para la identidad de sistema (o régimen) político con sistema (o régimen) jurídico, ver BIDART Campos, Germán J., El régimen politico. De la politeia a la respublica, Ed. Ediar, Buenos Aires.

3 Ver HerRendorf, Daniel E., Introducción a la fenomenología egológica (en el libro de Carlos Cossio: Radiografía de la teoría egológica del derecho, Ed. Depalma, Buenos Aires); y Las corrientes actuales de la filosofía del derecho, Ed. Ediar, Buenos Aires. 
Queda ya propuesto, sin que hayamos de entrar en profundidad al desarrollo iusfilosófico, que esa realidad no es un apósito que se confiera a los derechos humanos por la sola circunstancia de que en el sistema tenga unas normas formuladas que reconozcan y declaren derechos humanos.

En otras palabras, un sistema es y funciona como sistema de derechos humanos cuando en ese sistema las conductas jurídicas de los hombres - gobernantes y gobernados - los hacen realidad en la vida jurídica, en el mundo juridico, cuya realidad es precisamente una realidad de conductas en dimensión sociológica. Los derechos humanos se definen, así, como las conductas que los respetan y promueven.

A la inversa, un sistema no es y no funciona como sistema de derechos humanos por el puro hecho de que en él haya normas (que son entes lógicos) que formulen y declaren derechos. Ello porque el derecho no es norma, sólo norma, y nada más que norma.

A esta afirmación prestan aval en Argentina escuelas iusfilosóficas como la egología de Carlos Cossio y el trialismo de Werner Goldschmidt ${ }^{4}$.

\section{LA NECESIDAD DE LA AXIOLOGİA}

Cuando se encara con realismo lo que es un sistema de derechos humanos es posible ponerse a pensar qué relación guardan con él los valores. $Y$ de inmediato se hace patente que ni la filosofia de los derechos humanos, ni la ciencia de los derechos humanos, ni el derecho de los derechos humanos pueden ser lo que son si dejan de lado eso que unos llaman estimativa, otros axiología jurídica, otros dikelogía, pero que con una denominación o con otra es asunción de los valores y de su realización.

¿Por qué decimos esto? Porque si solamente encaráramos normas sobre derechos humanos, si solamente estudiáramos normas, si cayéramos en el reduccionismo de definir el derecho exclusivamente como un sistema de normas, si despreciáramos la noción (de raíz husserliana) de que las normas dicen "algo" acerca de otro "algo" que siempre son conductas humanas, sería difícil que alrededor de un sistema de normas (que

: Ver Cossio, Carlos, Radiografía de la teoría egológica del derecho, cit., que contiene una sinopsis de obras anteriores del autor, entre ellas: La teoría egológica del derecho y el concepto jurídico de libertad. 2. ${ }^{a}$ ed., Ed. Abeledo-Perrot, Buenos Aires; GoldschmidT, Werner, Introducción filosófica al derecho, 4. ${ }^{a}$ ed. Ed. Depalma, Buenos Aires. 
son entes lógicos, menciones o descripciones de conductas, como se prefiera) pudiéramos incardinar los valores que son propios del sistema de derechos humanos.

\section{¿Por qué sería difícil?}

En primer lugar porque, desde cualquier postura filosófica, parece innegable la noción de Dilthey que se enuncia afirmado que el valor es valor para un espiritu, para un «alguien" que valora. $Y$ ese alguien que valora es el hombre, el ser humano, la persona humana. Aceptada esta verdad, adviene otra: es el hombre el que realiza los valores: los valores estéticos en sus obras de arte, y los valores éticos y jurídicos en sus conductas.

$Y$ ya vamos aproximándonos a comprender que el hombre para quien el valor es valor porque valora, es el mismo hombre que fenomeniza el valor en lo que hace o en lo que omite, es decir, en objetos culturales, y no en objetos lógicos como son las normas.

Si lo que hace o lo que omite al desplegar su libertad lo hace o lo omite en su vida - porque vive-, hallamos la realidad que Ortega llamó «radical» porque en ella «radica» todo lo demás. $Y$ esa realidad radical en la que radica todo lo demás - también los valores- es la vida personal de cada uno, la vida biográfica de cada hombre de carne y hueso, para quien esa vida es "su» vida, intransferible y propia, la que él solamente puede vivirsela a sí mismo, y nadie por él.

El hallazgo de la vida humana, del hombre que es su protagonista exclusivo, y de los valores, nos va a conducir a la realidad del derecho y, por ende, de los derechos humanos. Pero antes vale hacer una pausa para insistir en que al toparnos con el hombre, con su vida, con los valores, y con el derecho, es imposible una filosofía jurídica y una ciencia jurídica sin axiología, o sea, neutra al valor.

No solamente un repudio en bloque a la axiologia es visible en el positivismo jurídico originado por el maestro Hans Kelsen, sino también en los desarrollos de sus, por cierto, ilustres seguidores. Sin ir más lejos, el destacado administrador del Hans Kelsen-Institut de Viena, Dr. Robert WALTER, escribió recientemente: «Que la Teoría pura del Derecho pretende ser una teoria dirigida a la dogmática del Derecho positivo, lo cual resulta del hecho de que sólo se quiere describir (reflejar) su objeto, pero no valorarlo». «pura» 5 .

Esto resulta especialmente subrayado con su designación de

5 WALTER, Robert, "Las normas jurídicas", separata de Cuadernos de filosofia del derecho, Madrid, s/f., pág. 107. 
Destacamos este párrafo porque en él se advierte lo que, después de la teoria egológica, puede considerarse una error ontológico. Dice Walter, en estricta ortodoxia kelseniana, que describir el objeto de la dogmática jurídica implica no valorarlo, y sugiere finalmente que una actitud valorativa restaría pureza a la descripción. Esto sólo puede afirmarse partiendo de la base, a nuestro juicio errónea, de que el objeto de estudio del jurista no contiene por sí y en sí ningún valor. Pero pensemos, por ejemplo, que es imposible conocer una obra de arte prescindiendo de su belleza o de su fealdad, porque en esa prescindencia queda desvirtuada la obra de arte en su propio ser: si no es bella o fea, o no exhibe cualesquiera valores que se quiera predicar de ella, no es un objeto cultural y, por lo tanto, no estamos hablando de una obra de arte.

De igual modo, describir el derecho con prescindencia de su valor es, sin más, describir una norma, una regla de derecho, o un juicio por el estilo; pero eso, así expresado, liberado y mutilado de todo valor, no es derecho ni puede serlo.

En esta trampa axiológica cayó Kelsen visiblemente, lo que no significa que esta prescindencia del valor pueda ser útil para conocer normas (es decir, objetos lógicos); pero no nos habilita para, con ese mismo procedimiento, conocer conductas, o sea, conocer el derecho en su viviente realidad (es decir, objetos, culturales y, en la emergencia y en fe husserliana, egológicos en cuanto la conducta es vida humana viviente). $Y$ otra vez aparece la vida, la del hombre.

La noción kelseniana insistida y exaltada por Walter en el sentido de la «pureza» que ostenta una descripción neutra al valor, convierte en sinónimos «impureza" y "valiosidad", desde que incluir al valor en el derecho sería incurrir en impureza. Entonces, para salvar la pureza hay que marginar al valor, según el kelsenianismo.

No obstante, esa sinonimia no puede aceptarse en las ciencias sociales ni, por ende, en la ciencia del derecho, que es una ciencia social; y no puede aceptarse porque todo to que estas ciencias tienen de sociales lo tienen de valioso ${ }^{6}$.

\section{EL ÁMBITO DONDE RADICAN LOS VALORES}

Ya efectuada la reivindicación del valor en la ciencia del derecho y en esa realidad que ella describe como objeto suyo, tenemos que retomar

6 Respecto de la actualidad del normativismo y de las ideas de sus seguidores, así como su réplica, ver HeRRENDORF, Daniel E., Las corrientes actuales de la filosofia del derecho, cit. 
el hilván con la vida humana y con el hombre, así como con los valores que son valores para él, para su espíritu. Si se nos corta ese hilván no podemos arribar a los derechos humanos que, aunque resulte redundante, son «de-el-hombre».

Pues bien, ¿en qué ámbito, en qué parte, en qué sector de la vida humana radican los valores? No vacilamos en sostener que los valores jurídico-políticos radican en la conducta humana compartida, en esa conducta que, como intrínsecamente jurídica ${ }^{7}$, COSsío llamó conducta en interferencia intersubjetiva, porque en ella participan al menos dos personas; por eso es viable proponer que los valores jurídicos exhiben realmente la dualidad de un sustrato y un sentido fundidos en un único objeto cultural que es la conducta jurídica valiosa, siendo el sustrato de esos mismos valores siempre la conducta humana, como el sustrato de los valores estéticos es siempre un objeto mundanal ( $y$ no egológico, como la conducta): el mármol o la piedra en la estatua, la tela pintada en el cuadro, el sonido en la música, etc.

Si los valor $\overline{e s}$ jurídicos radican en un sustrato que es la conducta humana compartida, ninguna estimativa, ninguna axiología, ninguna dikelogía podrán prescindir de este dato de la experiencia jurídica: no hay ninguna conducta que ontológicamente sea neutra al valor; toda conducta es siempre valiosa (con signo positivo o con signo negativo), como toda obra de arte es siempre valiosa porque siempre está impregnada de valor estético, sea que la valoremos como bella o como fea.

La afirmación de que no hay conducta humana neutra al valor se identifica con la otra de que es esa misma conducta el sustrato de los valores jurídico-politicos, por to que en el tema relacional de valores y sistema de derechos humanos es imposible, en buena filosofía, prescindir de las conductas, o lo que le es equivalente, quedarse solamente con las normas. Los valores que hayan de ser propios de un sistema de derechos humanos habrán de ser valores que se encarnen o que cobren realidad

7 Seria extremadamente largo - y ajeno a los fines de un ensayo sobre los valores en un sistema de derechos humanos- explicar por qué las conductas siempre son jurídicas. Pero valga entonces una aclaración sinóptica: las conductas, en la medida en que siempre son licitas o ilícitas, están dentro del círculo de la juridicidad. La egología explica - por ejemplo- que una norma jurídica completa contempla siempre las conductas ilicitas en forma de deber ser imputativo - perinorma-y las conductas lícitas en forma de deber ser existencial, que involucra el problema jurídico de la libertad -endonorma-. Asimismo, el axioma ontológico de la libertad jurídica permite expresar a ciencia cierta que todo lo que no está prohibido está jurídicamente permitido, cubriendo así lo que la dogmática clásica ha denominado "lagunas del derecho". Por razones de brevedad, nos remitimos a Carlos Cossio, La Teoria egológica del derecho y el concepto jurídico de libertad, cit.; y HERRENDORF, Introducción a la fenomenologia egológica, cit. 
fenoménica —en el caso, social- en las conductas humanas también juridicas.

Sólo en sentido análogo cabrá decir que las normas son justas o injustas en relación a cómo sean las conductas a las que esas normas se refieren mentándolas. No de otro modo, porque los valores no deambulan en el sector de los objetos lógicos.

\section{EL SISTEMA DE DERECHOS HUMANOS EN LA REALIDAD SOCIAL DE LAS CONDUCTAS}

¿Qué estamos reivindicando con estos prolegómenos? Que los valores propios de un sistema de derechos humanos sólo convierten a un sistema en sistema de derechos humanos cuando conductas jurídicas hacen de sustrato a aquellos valores con signo positivo y cuando erradican a los valores con signo negativo que se les oponen como disvalores.

El centro de gravedad de un sistema de derechos humanos - como en todo sistema jurídico- se compone así de dos elementos dialécticamente relacionados: "conductas" valiosas que son sustrato de "valores" con signo positivo (porque si tienen signo negativo hay disvaliosidad, lo que equivale a reconocer que no existe un sistema de derechos humanos). Sustrato (conducta) y valor (sentido) se fusionan en «ser-un-objeto-cultural»".

Si, en cambio, entendemos a un sistema de derechos humanos únicamente como un sistema de normas que los declaran favorablemente, nos quedamos errantes en el área de un producto lógico como son las normas. ¿Y dónde colocamos a los valores, si hemos extraviado al hombre cuya vida consiste en un despliegue de conductas y se trama con conductas, y si simultáneamente hemos opacado aquel sentido direccional del valor hacia el hombre que venia encapsulado en la fórmula de Dilthey?

El hombre es un ser mundanal, un ser que está en el mundo, situado y situacionado; que es persona, y que co-existe y con-vive con los demás. La vida jurídica es una realidad compartida, coexistencial, hecha con la vida biográfica de los hombres protagonistas de esa convivencia, de ese vivir juntos en común en un tiempo existencial y en un lugar determinado. Cuando tantas veces, aun desde los normativismos más crudos, se repite que el derecho es un fenómeno social, no siempre se le asigna a esa afirmación todo su sentido. Mal sería el derecho un fenómeno social si consistiera solamente en normas que, repetimos hasta el hartazgo, son entes lógicos. Un fenómeno social, una realidad social, una realidad jurídica jamás pueden reducirse a expresiones semánticas que dicen algo en las 
normas, porque lo dicen acerca de otro algo que es la conducta; y ésta sí es una realidad, una realidad jurídica, la que da emplazamiento, sede y sustrato a los valores jurídico-políticos.

Así como Cossío —siguiendo a Del Vecchio- acuñó la locución de conducta en interferencia intersubjetiva para definir aquello en que consiste el derecho, Goldschmidt dio curso a la expresión «mundo jurídico" para también connotar al derecho en su trialidad de dimensión sociológica, dimensión normológica y dimensión “dikelógica» (o del valor).

Pues bien, si con mucho empirismo nos desplazamos en un mundo de conductas humanas compartidas como lo venimos proponiendo, con similar empirismo debemos colocar como dato de la experiencia jurídica a esas mismas conductas a efectos de que, valorándolas con las valoraciones promedio que circulan en una sociedad democrática y abierta, podamos saber si el sistema bajo análisis realiza o no los valores que son propios de un sistema de derechos humanos. Y a tales valores sólo los vamos a encontrar en las conductas de los hombres que conviven en el sistema que sometemos a nuestro conocimiento.

De lo expuesto se desprenden dos cosas importantes: una, que para conocer los sistemas político-jurídicos y encuadrarlos o no en la categoría de un sistema de derechos humanos, es imposible prescindir de la estimativa, o sea, de la valoración; y otra, que a los valores y disvalores sólo los vamos a hallar como sentido de un sustrato que es la conducta humana, o sea, en la dimensión sociológica y no en la normológica.

\section{EL CONJUNTO CULTURAL DE UNA SOCIEDAD Y LOS VALORES}

Pero esto no es todo. También resulta posible una búsqueda axiológica en un ámbito ajeno a las conductas. Hace algunos años formulamos una tentativa de propuesta para también relacionar los valores con lo que Duverger ha llamado los conjuntos culturales. La segunda, era $-y$ es- la siguiente: un conjunto cultural determinado, que se compone de ideas, creencias, valoraciones sociales y representaciones colectivas, ¿puede ser o es sustrato de valores? ${ }^{8}$ Por supuesto que sólo de modo analógico o aproximado adquiere sentido el interrogante, desde que un conjunto cultural no es un conjunto de conductas. Pero ¿cabe asimilarlo a las conductas? La propuesta consistia en averiguar si una sociedad y su conjunto

- Ver Bidart Campos, Germán J., Valor, justicia y derecho natural, Ed. Ediar, Buenos Aires, pág. 193: Los conjuntos culturales, ¿sustratos del valor? 
cultural admiten «materializarse» de alguna manera como objeto situado fuera del sujeto que lo observa y lo somete a su conocimiento, y si en esa operación cognoscitiva y valorativa es viable llegar a afirmar que el ambiente social integrado por la sociedad y su conjunto cultural funciona como un ámbito que presta soporte a los valores.

De inmediato es imprescindible aclarar que, aunque contestemos afirmativamente, lo único que contendrá la respuesta - porque es lo único que nuestro conocimiento alcanzará a descubrir-es lo siguiente: tal o cual conjunto cultural de una sociedad sirve de apoyo a tales o cuales valores lo que equivale a predicar que tales o cuales valores están presentes en las valoraciones que se manifiestan en lo que, con vocabulario orteguiano, llamariamos lo que «se» piensa, «se « cree, "se» representa colectivamente (¿quién?, ese sujeto que con el mismo autor apodaríamos «la gente»). Así como en las conductas se manifiesta y hace ostensible -en cuanto sustrato- un valor o varios, en un conjunto cultural también se manifiestan y hacen presencia las preferencias axiológicas.

Por supuesto que aquello en que consiste la conducta como sustrato del valor difiere bastante, o mucho, de aquello en que consiste un conjunto cultural formado de ideas, creencias, representaciones y valoraciones colectivas. No obstante, si tomamos para proseguir la reflexión un texto de Jean BAECHLER ${ }^{9}$, damos continuidad provechosa a ella; dice dicho autor que «una ideología es una formación discursiva polémica, merced a la cual una pasión trata de realizar un valor a través del ejercicio del poder en una sociedad".

Pues bien, sustituyamos el vocablo «ideologia» por el vocablo «conjunto cultural», y extraigamos del párrafo transcripto la noción de que los hombres que en una sociedad comparten un conjunto cultural tienden a plasmar sus ideas, sus creencias, sus valoraciones, sus representaciones colectivas en la realidad de su convivencia mediante la acción, que es como decir, mediante sus conductas. Entonces, cuando aprobamos la idea de que los conjuntos culturales tienen vocación de impeler a la acción, estamos en condiciones de aceptar que los valores circulantes en un conjunto cultural poseen capacidad de activismo para llegar a convertir (con la concurrencia de una serie de factores de otro tipo) a esos mismos valores en sentido de un sustrato que - por supuesto- ya no consiste en ideas, ni en creencias, ni en representaciones colectivas, sino en ser conducta humana.

Es, ni más ni menos, el fenómeno de las ideas, las valoraciones, y las representaciones en cuanto elementos de lo que se muestra y apoda como el factor cultural, o el presupuesto cultural, o el condicionamiento cultural de un sistema político-jurídico, dato éste que los politólogos asumen cuando encaran cuáles son los marcos del sistema.

9 ¿Qué es la ideología?, Ed. Emecé, Buenos Aires, pág. 55. 
No es un secreto para la experiencia que sociedades abiertas cuyo conjunto cultural acoge valoraciones democráticas están mejor predispuestas «culturalmente» para convivir en un sistema democrático y para hacer realidad a un sistema de este tipo, que otras cuyos conjuntos culturales no auspician similares valoraciones. $Y$ tampoco es un secreto que lentamente un sistema totalitario o autoritario vaya siendo perforado hasta arribar a una transición democrática, cuando desde el conjunto cultural de la sociedad aprisionada en ese sistema, el activismo de los valores propugnados por ella alcanza progresivamente a realizarlos en las conductas, con lo que el sistema no democrático se transforma para dar cabida a su opuesto, tal como lo demuestra la experiencia de Europa Oriental y del Centro a partir de 1989.

Las precedentes disquisiciones han procurado poner de relieve que un sistema de derechos humanos, que no se hace, ni se funcionaliza, ni existe solamente en base a ideas y valoraciones, precisa, para su existencia funcional y su realización mediante las conductas humanas, que el factor cultural —digase si se quiere: el conjunto cultural de su sociedadcomparta, asimile y opte por unos valores propicios al sistema de derechos humanos.

Aquí subyace, pues, el alcance de la propuesta que sugería verificar si un conjunto cultural puede considerarse, de alguna manera, como sustrato, soporte, o apoyatura de valores en cuanto valores deseables, de valores posibles, de valores que una sociedad pretende ver radicados en la conductas de sus integrantes.

Como saldo rescataríamos algo: sea o no acertada la propuesta, sea o no compartida la idea albergada en ella, parece verdad que los valores del sistema de derechos humanos requieren, para la funcionalidad del sistema, un cierto acuerdo social, un cierto consenso de base, un entendimiento societario en torno de un programa o proyecto común para la convivencia en el sistema. Traducido a otra expresión, quiere decir que los valores que resultan acogidos en un conjunto cultural tienen fuerza de impulsión para coadyuvar a la realización de un sistema político-jurídico.

\section{EL DEBER SER EXISTENCIAL}

El tema de las valoraciones que circulan en una sociedad, y de los valores que incitan su proyecto societario de vida en común guarda parentesco con una tesis cara a la escuela egológica de Cossío. Es la tesis del deber ser existencial. Véamosla brevemente. 
El proceso axiológico que conduce a una sociedad a vivir ciertos valores juridicos y no otros, plantea el programa iusfilosófico que precisamente la egología encara bajo esa denominación de «deber ser existencial.»

Tal vez hoy sea fácil explicar qué es ese deber ser existencial, valiéndonos de un ejemplo reciente.

Los alemanes que durante décadas pretendían ejercer su derecho de salir y de entrar de y a Alemania Oriental no podian hacerlo sin correr graves riesgos. Pero estaban impulsando el cambio que finalmente se produjo al caer el muro de Berlín en 1989 y al unificarse las dos Alemanias en 1990. Esa tensión social creada por los hombres con conciencia de sus derechos germinó bajo la forma de una licitud positiva: entrar y salir a y de Alemania Orienta. ¿Qué deber-ser jurídico estaban viviendo los alemanes? No estaban viviendo el deber ser de las normas prohibitivas entonces vigentes, porque si lo hubieran vivido habrían vegetado en una obediencia ciega a la prohibición de salir, o al menos habrian vivido pacíficamente sin desonancias ni protestas ni rebeldias. Pero el vivir biográfico y real de los alemanes incluía protestas, rebeldías, disonancias, gestos y conductas de desobediencia: no estaban viviendo el deber ser lógico que se tiene como propio del derecho positivo. Estaban viviendo el deber-serexistencial.

Así, se advierte y compromete claramente que lo que se espera vivir en el futuro siempre se proyecta ya desde el presente, no como un deber ser, porque carece de actualidad estricta, pero sí como un deber-ser-existencial, como una posibilidad que llegará a ser realidad. Por eso, los hombres que conviven socialmente viven el deber ser existencial de lo que anhelan con pretensión de futuridad, proyectivamente. Esta noción egológica se respalda en ideas de Heidegger, que definía el contenido sustancial de la vida biográfica de cada uno como «el poder ser una posibilidad siendo la posibilidad que llega a ser". La libertad de cada ser humano, si no estuviera ligada y dirigida a un futuro, sería una explosión de libertad sin dirección a nada, pero cuando se liga a un futuro, ese futuro aparece como algo "que llega a ser», no como algo que ya es (porque si así fuera, estaría siendo) sino como algo que será.

Esa posibilidad que llega a ser -en la expresión heideggerianafue para los alemanes la libertad. Esta libertad, que era solamente una posibilidad que llegará a ser, solamente llegaría a ser efectivamente si esos mismos alemanes sentian que sus vidas biográficas eran «un poder ser esa posibilidad."

Hay, entonces, dos partes en la frase de HEIDEGGER: a) poder ser una posibilidad b) siendo la posibilidad que llega a ser.

Las vidas alemanas supieron que la libertad podía ser una posibilidad (primera parte de la frase) y que esa posibilidad así encarnada re- 
presentaba la posibilidad que llegaria a ser (segunda parte de la frase), como finalmente la experiencia mostró que llegó a ser.

Entre tanto, vivieron un deber ser existencial, el deber ser existencial de su libertad, que era un anhelo proyectivo y futurizo.

Si trasladamos esta noción egológica del deber ser existencial al tema de los derechos humanos $-y$ el ejemplo dado los comprometía en alto grado - cabe decir lo siguiente: los derechos humanos consisten en las conductas de aquellos que los respetan. Pero iy si el Estado no los respeta sino que los viola? Entonces los derechos humanos consisten en la conducta de quienes luchan por ellos. El intento, el anhelo, el proyecto, la rebeldía por la vigencia de los derechos constituyen, en ese caso, una conducta que por sí misma delimita el círculo de la juridicidad de los derechos.

Con suficiente vinculación respecto de lo recién comentado, el sistema de valores culturalmente acogido en un ambiente societario puede asimilarese a lo que, con vocabulario de Elías Díaz, calificamos como la legitimidad sociológica, en tanto ésta expresa la legitimidad que las valoraciones sociales asignan a un sistema jurídico-político, sea que éste exista realmente en esa sociedad, sea que no exista pero que se imagine como debiendo existir, en discrepancia con el existente. En este último supuesto, la puja entre la legitimidad sociológica y la legitimidad legalizada que discrepa, trasunta una oposición en la que la primera es capaz de perforar a la segunda y de llegar a reemplazarla, con lo que ratificamos nuevamente que el conjunto cultural de la sociedad, al postular un sistema de valores con legitimidad sociológica, le brinda apoyatura y tiende a fenomenizarlo empiricamente.

\section{LA FUNCIÓN LEGITIMADORA DE LOS DERECHOS HUMANOS}

Sin renegar ni abdicar del estudio filosófico acerca de la fundamentación de los derechos humanos, conviene asumir con realismo el importante problema de cómo instalar y funcionalizar un sistema de derechos humanos, cualquiera sea el sustento iusfilosófico que, en unidad o pluralidad, le preste explicación doctrinaria. En este plano de la vigencia sociológica cobra relevancia el consenso social, el ya mentado acuerdo de base, la convergencia - aun desde diversidad de líneas filosóficas- en unas valoraciones o un sistema de valores culturalmente compartido, por aquello de que los hombres solemos comportarnos conforme a aquello en lo que creemos, y a la inversa solemos no hacer aquello en lo que no creemos. La «creencia» coincidente en un sistema de valores propio del sistema de derechos humanos afluye como consenso y entendimiento societarios a favor del sistema de derechos humanos. 
Si se admite esto, se recala en la función legitimadora que el sistema de valores propio de un sistema de derechos humanos juega en la integridad del sistema jurídico-político. Valores, conjunto cultural, legitimidad sociológica, se conjugan en orden al consenso favorable en torno al sistema de derechos humanos.

Esos valores del sistema de derechos humanos se expanden, entonces, a todo el orden jurídico-político, a todo el sistema, a todo el régimen, fenómeno que bien se avizora cuando a los derechos humanos se los funcionaliza con ambivalencia o bifrontalidad, es decir, de frente y en oponibilidad ante un doble sujeto pasivo: no sólo ante el Estado, sino además ante sujetos particulares o privados (cada hombre titular frente a los demás hombres).

Los derechos humanos así integrados al orden público jurídico del Estado hacen de principio de unidad y coherencia de dicho orden, en cuanto éste se engarza en el sistema de valores que aquéllos presuponen, y se informa en sus pautas.

No otra cosa significa la fórmula del artículo 9.1 de la Constitución española cuando afirma que los ciudadanos y los poderes públicos están sujetos a la Constitución y al resto del ordenamiento jurídico. Sin norma alguna de ese tipo, el derecho 'constitucional argentino admite una interpretación equivalente: la Constitución vincula y obliga tanto a los gobernantes como a los gobernados. Desde la Constitución, entonces, los derechos humanos y los valores que les son reciprocos irradian su función legitimadora y exigen su realización —en dimensión sociológica- a los órganos gubernamentales y a los particulares.

VIII. LOS VALORES Y EL «OBJETIVISMO»

Es menester de inmediato circunvalar rápidamente a los valores para alguna adición complementaria al tema que no ocupa.

Qué son los valores, genera un interrogante al que la variedad de respuestas filosóficas no contesta con unanimidad. Es cierto que para propugnar un sistema de derechos humanos con su sistema de valores propicio no hace falta - ya lo adelantábamos poco antes de alguna maneraasumir coincidencias en una misma base folosófica; pero aún así, es requerible un entendimiento mínimo en torno de los valores.

Tal entendimiento minimo gira en torno a algo fundamental que es lo siguiente: no se puede colocar a los valores como subsuelo de un sistema de derechos humanos con ninguna de estas dos posturas: 
a) afirmando que los valores propios de un sistema de derechos humanos son los que subjetivamente resulten valores para cada cual, conforme a su impresión personal exclusivamente;

b) afirmando que los valores propios de un sistema de derechos humanos son los que al gobernante de turno se le ocurre que sean o que son valores, lo que a la postre es otra expresión de total relativismo subjetivista.

Descartadas estas dos posiciones, creemos que las demás que asuma cada escuela filosófica son aptas para generar un entendimiento mínimo sobre los valores.

¿Por qué nos atrevemos a acoger tan vasta serie de enfoques sobre los valores? Porque para el mínimo entendimiento societario en torno de ellos, alcanza con conferirles objetividad fuera de la pura impresión, o comprensión, o vivencia, o valoración subjetivas, de forma que reconocerlos, descubrirlos, realizarlos, no dependa exclusivamente de una inmersión personal en la inmanencia de la intuición de cada uno, o de su aprehensión, o de su racionalidad. Hay que ir de alguna manera hacia afuera de uno mismo para apoyar la valoración en algo objetivo, externo a mi yo, de modo que en ese ir hacia afuera, hacia lo externo ( $\sin$ que ahora importe qué entidad tenga tal externalidad objetiva), se haga posible coincidir con las valoraciones ajenas de otros sujetos normales colocados en posición de semejante objetividad.

Si hubiéramos de decirlo de otra manera, diríamos que hay que lograr objetivamente la posibilidad de compartir socialmente una similar valoración en torno de aquello que se valora; para nuestro caso, de las conductas jurídicas que, como sustrato del valor, son objetos culturales egológicos. (Por reflejo, valoramos a la par las normas que mientan o describen esas conductas.)

La objetividad del valor podrá radicar, para unas escuelas filosóficas, en una idealidad pura equivalente al derecho natural; para otras, en el conjunto cultural propio de un ambiente societal; para algunas, en el consenso societario, o en la tradición, o en la ética, o en las necesidades humanas, etc. En fin, esto es sólo y apenas un muestrario de posibles disensos filosóficos que, aun así, no resienten el tan mentado entendimiento mínimo sobre los valores, que se nos presenta como necesario para conferir base última a un sistema de derechos humanos.

Más no es dable avanzar, porque no se ignora que algunas iusfilosofías son monistas en cuanto a aceptar un solo y único valor jurídico, que es la justicia; en tanto otras pluralizan a los valores en un plexo o haz de varios o de muchos; $y$ acá nuevamente no existe unanimidad en cuáles sean los que integran ese plexo plúrimo. 
Cuando en la coexistencia compartida sus protagonistas asumen un entendimiento vital, intrasocietal e intersubjetivo acerca de un sistema de valores cuyo eje sea la dignidad humana y los derechos personales, se desemboca en el punto crucial para un sistema de derechos humanos: el que para ser tal, un sistema jurídico-político no puede crear a su propia y entera voluntad un sistema de derechos, o no crear ninguno. Este punto es crucial precisamente por la sencilla razón de que en el sistema jurídicopolitico los derechos del hombre no dependerán de la discrecionalidad arbitraria de pocos, de muchos, o de todos, sino del consenso aprobatorio de un conjunto de hombres normales competentes para valorar - parafraseando a Perelman-, que valoran guiándose por el sistema de valores que es propio de la filosofía de los derechos humanos.

\section{SISTEMA DEMOCRÁTICO, DERECHOS HUMANOS Y VALORES}

A esta altura del boceto diseñado se nos coloca por delante la naturaleza del sistema jurídico-político en el que se incardina un sistema de derechos humanos. No hay que vacilar en reconocer que nos hallamos ante un sistema democrático. Pero democrático no porque semánticamente aparezca el calificativo en las definiciones teóricas o, acaso, en las denominaciones normativas y oficiales que se adjudican algunos Estados. Democrático porque responde al esquema modelo que han tomando en cuenta los pactos internacionales sobre derechos humanos —universales y regionales-.

Y ya que de algún modo nos acabamos de deslizar marginalmente a una cuestión de lenguaje, como es el uso polivante y a veces hasta equívoco de una misma palabra (democracia), hemos de afrontar otra muy vinculada a los valores. Por un lado, a qué se llama valores, lo que requiere previamente asumir qué son los valores. Por otro lado, dónde y cómo se realizan esos valores.

En el plano constitucional, sin mayor pretensión filosófica, pero con el sentido pragmático de una propuesta que anida un proyecto de entendimiento y de convivencia societarios, tenemos el ejemplo de España, cuya Constitución de 1978 en su artículo 10 afirma que España propugna como valores superiores de su ordenamiento juridico a la libertad, la justicia, la igualdad y el pluralismo político. No todo lo que en esta norma viene mentado con el nombre de valores tiene correspondencia en el enunciado de algunos plexos axiológicos propuestos por algunas escuelas filosóficas.

Respecto de la Constitución argentina de 1853-1860, hay doctrina que a los seis objetivos enumerados en su preámbulo (unión nacional, justicia, 
paz interior, defensa común, bienestar general y libertad) los reputa valores.

Con un alcance práctico, no nos desconcierta que un sistema jurídico-politico rotule como valores a algo que no tematiza la estricta iusfilosofía. La discordancia dimana seguramente de algo muy simple, como es el hecho de considerar valores a todos los bienes, o a todas las cualidades buenas de un determinado objeto, en oposición a los disvalores (o desvalores, o valores con signo negativo). No puede exigirse a las normas constitucionales un rigor filosófico en torno de los valores que, cuando empezamos a sumergirnos en la pura iusfilosofía, descubrimos sujetos a disputas epistemológicas.

En cambio, el detectar dónde y cómo se realizan los valores ya no es cuestión de tanta preferencia semántica. En efecto, si se nos quiere convencer de que los valores de un sistema de derechos humanos se realizan en un sistema normativo (el "dónde" se realizan) mediante la formulación de normas (el «cómo» se realizan), hemos de inmediato de reaccionar con negación rotunda. ¿Por qué? Porque aun con el más crudo normativismo cualquiera comprende que la realidad de los derechos humanos no radica en el hecho de su formulación normativa; las normas son entes lógicos, en tanto el derecho es un fenómeno social, un fenómeno de convivencia que es imposible agotar en el logicismo de las normas. Entonces, habrá que encontrar una realidad social que sea el «dónde» los derechos se realizan porque en esa misma realidad radican los valores, y otra realidad también social que sea el «cómo» se realizan.

Estamos personalmente seguros de que ese «dónde» es la conducta humana o la dimensión sociológica, y ese "cómo" es el hombre que fenomeniza su libertad en sus conductas.

\section{LA HISTORICIDAD DE LOS VALORES}

Resta alguna otra disquisición importante. La colocaremos bajo el rubro de la historicidad de los valores. El vocablo historicidad será usado de tal modo que resulte susceptible de compatibilizar nuestro enfoque con la pluralidad de iusfilosofias capaces de asimilarlo; también el iusnaturalismo, sea ontológico o sea deontológico.

Historicidad de los valores en el sistema de derechos humanos significará, entonces, que la comprensión y la realización de esos valores - por más trascendentes y objetivos que se los considere-son tributarias y dependen de un ambiente cultural, de aquel conjunto cultural al que, citando a Duverger, trajimos a colación anteriormente. Un filósofo argentino 
-Francisco Romero- nos dejó la noción de que los valores no son históricos, pero sí es histórico su ingreso en una comunidad. Goldschmidt, en su trialismo afín con la filosofia de los valores de Scheler y Hartmann, se ocupó sobradamente de escudriñar qué les acontece a los valores como entes ideales valentes y exigentes en la dimensión que él llamó "dikelógica», dentro del mundo jurídico. Cossío, por su parte, reafirmando la recia idea husserliana y heideggeriana en torno de la fenomenología y la mundanidad, confirma con Dilthey que el valor sólo es valor para un espiritu, y de ahí, en más, predica que ontológicamente no hay conducta humana que sea neutra al valor, lo que directamente lo conduce a radicar los valores jurídicos como sentido en la conducta humana como sustrato.

Todo lo que denominariamos la fenomenización del valor en lo que el hombre hace cuando se comporta como ser-en-el-mundo que co-existe y que con-vive con su prójimo, obliga a admitir que el sistema de valores que es propio de un sistema de derechos humanos está enquiciado en ( $y$ no desquiciado de) una circunstancia compuesta y condicionada (situada y situacionada) por múltiples ingredientes, presupuestos y marcos de diverso tipo (cultural, sociológico, económico, político, religioso, tecnológico, demográfico, geográfico, temporal, etc.). Es en esa circunstancia en la que coexisten, conviven y se comportan unos hombres situados y situacionados, en cuyas conductas como sustrato hallamos a los valores (con signo positivo o con signo negativo) como sentido. Mal puede, entonces, desgajarse y desvincularse a esos valores de la situación o circunstancia tempo-espacial signada históricamente y, desde el protagonismo de la vida de cada hombre, también signada biográficamente.

\section{EPILOGO}

En definitiva, dos lecciones como mínimo pueden rescatarse de estas reflexiones. La primera, para la filosofía en general, y para la filosofía del derecho en especial; es la lección de que no puede enceguecerse la mirada a los valores cuando nos preguntamos por el ser óntico y por el ser ontológico del derecho. La segunda, para la experiencia jurídica en el área del Derecho de los derechos humanos (sea Derecho constitucional, sea Derecho internacional de los derechos humanos); es la lección de que solamente los hombres, con lo que hacemos ( $y$ en el hacer va ínsito el omitir) cuando compartimos conductas en la convivencia sociopolitica, podemos y debemos convertir en realidad un sistema de derechos humanos dentro del sistema jurídico-político del que somos parte. 